\title{
Pd-catalyzed Dehalogenation of Aromatic Halides Under Solvent-free Conditions Using Hydrogen Balloon
}

\author{
Fei Chang, Hakwon Kim, ${ }^{\dagger}, *$ Byeongno Lee, ${ }^{\dagger}$ Hoon Gyu Park, ${ }^{\dagger}$ and Jaiwook Park \\ The School of Environment and Architecture, University of Shanghai for Science and Technology, Shanghai, 200093, P.R. China \\ 'Department of Applied Chemistry, Kyung Hee University, Gyeonggi-do 446-701, Korea. *E-mail: hwkim@khu.ac.kr \\ ¿Department of Chemistry, Pohang University of Science and Technology, Pohang 790-784, Korea \\ Received December 13, 2010, Accepted January 5, 2011
}

Key Words : Aluminum oxyhydroxide, Aromatic halides, Dehalogenation, Pd nanoparticles, Solvent-free reaction

The dehalogenation of aromatic halides possesses great significance not only in the removal of halogenated organic contaminants but also in the development of synthetic methodologies. ${ }^{1}$ Although several processes have already been well established to deal with toxic and even carcinogenic aryl halides, including adsorption and inactivation by oxidation and incineration methods, there is still a need for alternative treatments because conventional treatments unavoidably result in the production of highly deleterious by-products or huge amounts of waste materials. ${ }^{2}$ Solventfree (solvent-less) reactions have attracted much attention because they have several advantages over traditional reactions in organic liquid solvents: smaller reaction vessels, no organic medium to make less wastes, higher efficiency, easier operation, simpler purification and different product distribution. ${ }^{3}$ Chemical reductive dehalogenation, by means of the hydrogenolysis of the carbon-halogen bond to remove halogen atoms in molecules, has attracted attention from the field of both industry and academics. ${ }^{4}$

The reductive methods generally adopt transition metals as catalysts, such as nickel, ${ }^{5,6}$ palladium, ${ }^{7,8}$ rhodium, ${ }^{9,10}$ and platinum, ${ }^{11,12}$ among which palladium has been the most widely and intensively studied. Palladium (Pd) catalysts are technically important in accomplishing numerous organic transformations. Although commercial palladium sources, such as $\mathrm{Pd} / \mathrm{C}$ and $\mathrm{Pd} / \mathrm{Al}_{2} \mathrm{O}_{3}$, are extensively utilized as catalysts in synthetic chemistry, ${ }^{13,14}$ their efficiency and activity suffer greatly from wide distribution, poor dispersion of $\mathrm{Pd}$ particles deposited on the surface of supports, and the leaching of palladium when being processed. Hence, the preparation of unique $\mathrm{Pd}$ nanoparticles with unusually large surface has been intensively studied to catalyze the diverse reactions, especially the dehalogenations. ${ }^{15}$

Recently, a highly efficient heterogeneous Pd catalyst has been reported, which is composed of Pd nanoparticles entrapped in aluminum oxyhydroxide nanofibers $[\mathrm{Pd} / \mathrm{AlO}(\mathrm{OH})]$. It has been employed in various organic reactions such as the hydrogenation of alkenes and alkynes, the aerobic oxidation of alcohols, the alkylation of ketones with primary alcohols, the hydrogenolysis of epoxides, and $\mathrm{N}$-alkylation of primary amines with benzyl alcohols. ${ }^{16}$ Most recently, we have also reported that it could effectively catalyze the hydrogenation of alkenes and nitro-aromatics in solid state under solvent free conditions. ${ }^{17}$

To the best of our knowledge, only a few references are available for the dehalogenation of aromatic halides in solid state under solvent-free conditions using molecular hydrogen, which clearly has the advantages of non-toxicity and environmental efficiency, ${ }^{18}$ compared with other hydrogen sources such as formic acid and its salts, metal alkoxides, hydrosilanes, or Grignard reagents. ${ }^{20}$ Herein, we report highly effective and environmentally benign process for the dehalogenation of solid aromatic halides: the reactions of various solid aromatic halides are readily catalyzed by $\mathrm{Pd} /$ $\mathrm{AlO}(\mathrm{OH})$ without any solvent at ambient temperature in the presence of atmospheric hydrogen, and no deactivation of the catalyst, $\mathrm{Pd} / \mathrm{AlO}(\mathrm{OH})$, was observed for several times of recycle.

The reaction of 4-Cholophenol with molecular hydrogen initially produced phenol, the hydrogenolysis product of 4chlorophenol (1). ${ }^{20}$ Phenol (2) was further hydrogenated on aromatic rings under the same conditions and gave the cyclohexanone (3) with a very small amount of cyclohexanol $(<0.5 \%)$, showing a some activity of $\mathrm{Pd} / \mathrm{AlO}(\mathrm{OH})$ for the hydrogenation of aromatic rings and a much lower activity for that of carbonyl groups (Eq. 1). The conversion of 4-chlorophenol increased with time, but the selectivity for phenol decreased with time to approximately $60 \%$ due to the further hydrogenation of the aromatic ring of phenol into cyclohexanone (Table 1 , entry 1 ).

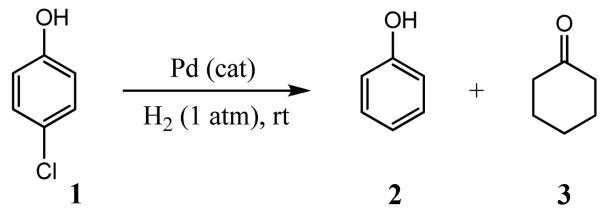

Comparative experiments were subsequently performed in normal organic solvents, and the catalytic efficiency of commercial palladium catalysts was also tested under solventfree conditions (Table 1). Contrary to previous reports, ${ }^{21}$ hexane, a non-polar solvent, provided the best conversion among all solvents employed (Table 1, entries 2-5). The 
Table 1. Dechlorination of 4-cholophenol under various conditions ${ }^{a}$

\begin{tabular}{ccccccc}
\hline Entry & Catalyst & Solvent & Base & $\begin{array}{c}\mathrm{Conv}^{b} \\
(\%)\end{array}$ & $\begin{array}{c}\mathbf{2}^{b} \\
(\%)\end{array}$ & $\begin{array}{c}\mathbf{3}^{b} \\
(\%)\end{array}$ \\
\hline 1 & $\mathrm{Pd} / \mathrm{AlO}(\mathrm{OH})$ & No & $\mathrm{No}$ & 82 & 63 & 38 \\
2 & $\mathrm{Pd} / \mathrm{AlO}(\mathrm{OH})$ & hexane & $\mathrm{No}$ & 82 & 91 & 9 \\
3 & $\mathrm{Pd} / \mathrm{AlO}(\mathrm{OH})$ & $\mathrm{MeOH}$ & $\mathrm{No}$ & 63 & $>99$ & $<1$ \\
4 & $\mathrm{Pd} / \mathrm{AlO}(\mathrm{OH})$ & acetone & $\mathrm{No}$ & 49 & 97 & 3 \\
5 & $\mathrm{Pd} / \mathrm{AlO}(\mathrm{OH})$ & EA & $\mathrm{No}$ & 68 & 98 & 2 \\
6 & $\mathrm{Pd} / \mathrm{C}$ & No & $\mathrm{No}$ & 9 & 85 & 15 \\
7 & $\mathrm{Pd} / \mathrm{Al}{ }_{2} \mathrm{O}_{3}$ & No & $\mathrm{No}$ & 18 & 48 & 52 \\
8 & $\mathrm{Pd} / \mathrm{CaCO}$ & $\mathrm{No}$ & $\mathrm{No}$ & 3 & $>99$ & $<1$ \\
9 & $\mathrm{Pd} / \mathrm{AlO}(\mathrm{OH})$ & $\mathrm{No}$ & $\mathrm{NaHCO}_{3}{ }^{c}$ & 95 & 83 & 17 \\
10 & $\mathrm{Pd} / \mathrm{AlO}(\mathrm{OH})$ & $\mathrm{No}$ & $\mathrm{Na}_{2} \mathrm{CO}_{3}{ }^{c}$ & 90 & 81 & 19 \\
11 & $\mathrm{Pd} / \mathrm{AlO}(\mathrm{OH})$ & $\mathrm{No}$ & $\mathrm{K}_{2} \mathrm{CO}_{3}{ }^{c}$ & $>99$ & 82 & 18 \\
12 & $\mathrm{Pd} / \mathrm{AlO}(\mathrm{OH})$ & No & $\mathrm{Cs}_{2} \mathrm{CO}_{3}{ }^{c}$ & $>99$ & 88 & 12 \\
13 & $\mathrm{Pd} / \mathrm{AlO}(\mathrm{OH})$ & No & $\mathrm{K}_{2} \mathrm{HPO}_{4}{ }^{c}$ & $>99$ & 92 & 8 \\
\hline
\end{tabular}

${ }^{a}$ Substrates $(0.20 \mathrm{mmol})$ and $\mathrm{Pd}\left(4 \times 10^{-3} \mathrm{mmol}\right)$ under $1 \mathrm{~atm} \mathrm{H}_{2}$ at room temperature. ${ }^{b}$ Estimated by $\mathrm{GC}$ and ${ }^{1} \mathrm{H}$ NMR. ${ }^{c} 0.15 \mathrm{mmol}$ of bases was used.

selectivity of the reaction in hexane was better than that under solvent-free conditions. The dechlorination of 4chlorophenol using $\mathrm{Pd} / \mathrm{AlO}(\mathrm{OH})$ offered a high conversion $(82 \%$, entry 1$)$, those using commercial palladium catalysts, such as $\mathrm{Pd} / \mathrm{C}, \mathrm{Pd} / \mathrm{Al}_{2} \mathrm{O}_{3}$ and $\mathrm{Pd} / \mathrm{CaCO}_{3}$, showed low conversions $(<20 \%$, entries $6-8)$. Aramendia and co-workers reported that $\mathrm{HCl}$ produced from dechlorination tends to be adsorbed on the activated carbon, leading to a progressive poisoning of $\mathrm{Pd} / \mathrm{C} .^{22}$ Based on this observation, we assumed that it would be efficient to add some bases for the removal of $\mathrm{HCl}$, a critical catalyst poison. Among several tested bases, $\mathrm{K}_{2} \mathrm{CO}_{3}$ was employed in subsequent experiments due to its easy availability (see Table 1, entries 9-13). Our solvent-free dechlorination reactions seem to proceed in a fused state, as we recently reported for the hydrogenation of solid aromatics using the same catalyst. ${ }^{17}$

To establish the generality of the catalyst system, various solid aromatic halides were subjected under the solvent-free conditions (Table 2). A simple haloarene, bromobiphenyl was dehalogenated selectively into biphenyl in almost quantitative yield (entry 1). The major products were phenols in the reactions of halophenols (entries 2-5); in the case of 1bromonaphthalen-2-ol the corresponding dehalogenated product was obtained in quantitative yield (entry 5). Our catalyst system was highly efficient for the dehalogenation of halobenzonitriles to give the corresponding benzonitriles (entries 6 and 7). Nitro group was also hydrogenated in the reactions of halonitroarenes (entries 8 and 9). Hydrogenolysis products were obtained in the reaction of benzylhalides (entries 10 and 11). Carbonyl groups were also hydrogenated under our conditions (entries 12 and 13). Particularly, a significant amount of a hydrogenolysis product, diphenylmethane was formed in the reaction of 4-chlorobenzophenone (entry 13). ${ }^{23}$

Finally, it is worth reporting that the $\mathrm{Pd} / \mathrm{AlO}(\mathrm{OH})$ catalyst could be recycled after simply washing it with water and
Table 2. Dehalogenation of various aryl halides under solvent-free conditions $^{a}$

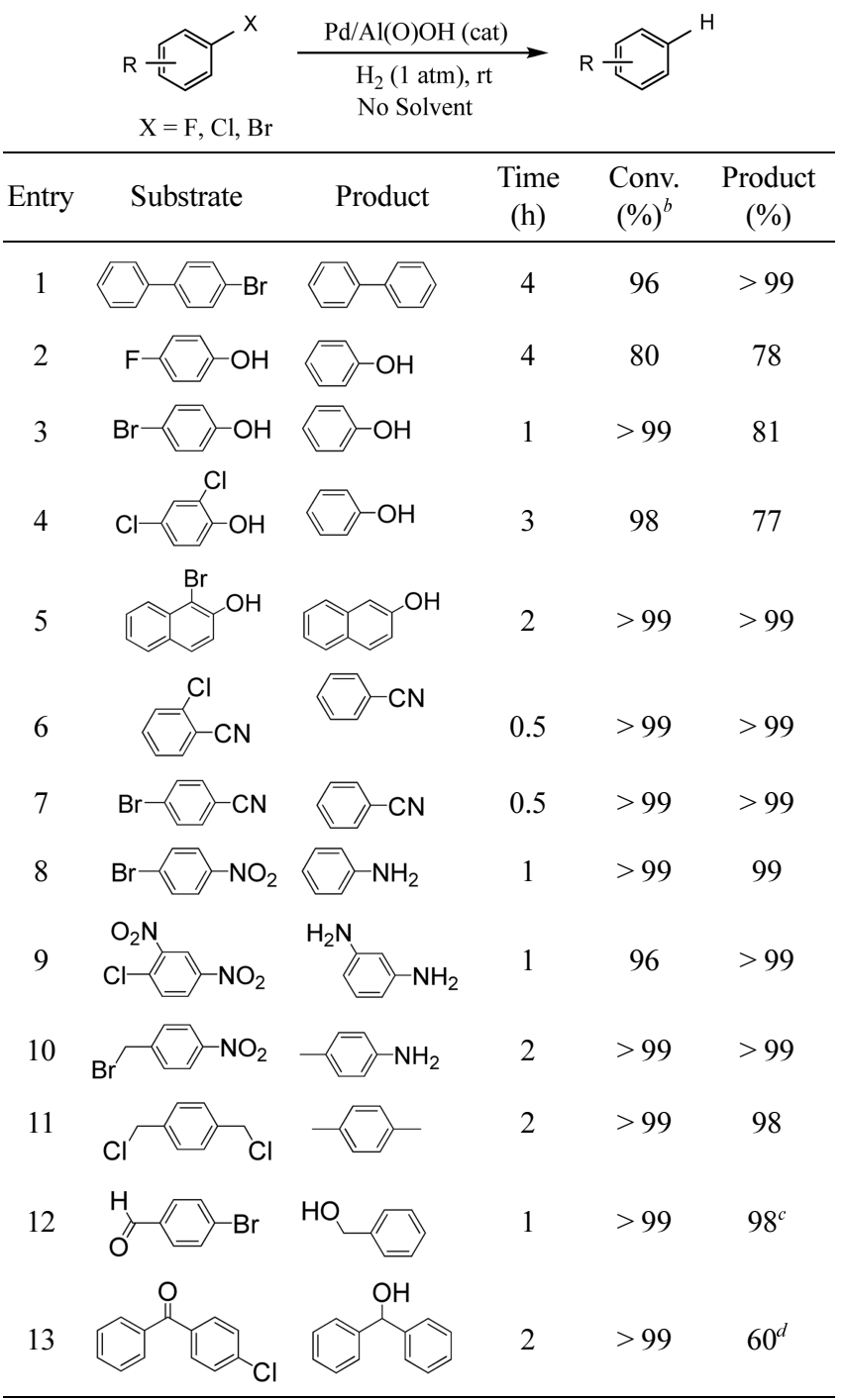

${ }^{a} \mathrm{~A}$ mixture of a solid substrate $(0.20 \mathrm{mmol}), \mathrm{Pd} / \mathrm{AlO}(\mathrm{OH})(2 \mathrm{~mol} \%$ of $\mathrm{Pd})$ and $\mathrm{K}_{2} \mathrm{CO}_{3}(0.15 \mathrm{mmol})$ was ground finely in a mortar and was allowed to react with $\mathrm{H}_{2}(1 \mathrm{~atm})$ under ambient conditions. ${ }^{b}$ Measured by GC and ${ }^{1} \mathrm{H}$ NMR. ${ }^{c} \mathrm{~A}$ trace amount of toluene was detected. ${ }^{d} \mathrm{~A}$ significant amount (40\%) of 1,1-diphenylmethane was detected.

Table 3. Reusability of $\mathrm{Pd} / \mathrm{AlO}(\mathrm{OH})$ by using 4-chlorophenol as a substrate $^{a}$

\begin{tabular}{lcccccc}
\hline Recycle & 1 & 2 & 3 & 4 & 5 & 6 \\
\hline${\text { Total conversion }(\%)^{b}}^{b}$ & $>99$ & $>99$ & 98 & $>99$ & $>99$ & $>99$
\end{tabular}

${ }^{a}$ Unless otherwise stated, 4-chlorophenol $(0.2 \mathrm{mmol})$ was used in every entry together with $\mathrm{Pd} / \mathrm{AlO}(\mathrm{OH})\left(\mathrm{Pd} 4 \times 10^{-3} \mathrm{mmol}\right)$ and $\mathrm{K}_{2} \mathrm{CO}_{3}(0.15$ mmol) under $1 \mathrm{~atm} \mathrm{H}_{2}$ environment at room temperature. ${ }^{b}$ Total conversion was confirmed by GC.

acetone, and then drying under vacuum. Our palladium catalyst could be used at least six times for the dechlorination of 4-chlorophenol without any loss of activity, similar to the our previous report. ${ }^{17}$

In summary, we explored the environmentally benign dehalogenation of solid aromatic halides using $\mathrm{Pd} / \mathrm{AlO}(\mathrm{OH})$ and hydrogen balloon under solvent-free conditions. All 
substrates in this study were efficiently converted into less toxic compounds with high conversions in short reaction time. In addition, the operation was accomplished in a simple way.

Acknowledgments. We acknowledge a Manpower Development Program for Energy \& Resources supported by the Ministry of Knowledge and Economy (MKE).

\section{References}

1. Alonso, F.; Beletskava, I. P.; Yus, M. Chem. Rev. 2002, 102, 4009.

2. Grushin, V. V.; Alper, H. Chem. Rev. 1994, 94, 1047.

3. (a) Martins, M. A. P.; Frizzo, C. P.; Moreira, D. N.; Buriol, L.; Machado, P. Chem. Rev. 2009, 109, 4140. (b) Tanaka, K; Toda, F. Chem. Rev. 2000, 100, 1025.

4. Haggblom, M. M.; Ahn, Y. B.; Fennell, D. E.; Kerkhof, L. J.; Rhee, S. K. Adv. Appl. Microbiol. 2003, 53, 61.

5. Zinovyev, S.; Shelepchikov, A.; Tundo, P. Appl. Catal. B 2007, $72,289$.

6. Keane, M. A.; Pina, G.; Tavoularis, G. Appl. Catal. B 2004, 48, 275.

7. Iranpoor, N.; Firouzabadi, H.; Azadi, R. J. Organomet. Chem. 2010, 695, 887

8. Navarro, O.; Marion, N.; Oonishi, Y.; Kelly, R. A.; Nolan, S. P. J. Org. Chem. 2006, 71, 685

9. Léger, B.; Nowicki, A.; Roucoux, A.; Rolland, J. P. J. Mol. Catal. A 2007, 266, 221.

10. Fujita, K.; Owaki, M.; Yamaguchi, R. Chem. Commun. 2002, 2964.

11. Mao, J.; Yan, X.; Gu, H.; Jiang, L. Chin. J. Catal. 2009, 30, 182.

12. Xu, Y.; Zhu, Y.; Zhao, F.; Ma, C. Appl. Catal. A 2007, 324, 83.

13. Monguchi, Y.; Kume, A.; Hattori, K.; Maegawa, T.; Sajiki, H. Tetrahedron 2006, 62, 7926 .

14. Cellier, P. P.; Spindler, J. F.; Taillefer, M.; Cristau, H. J. Tetrahedron Lett. 2003, 44, 7191.

15. Howe, R. F. Appl. Catal. A 2004, 271, 3.
16. (a) Kwon, M. S.; Kim, N.; Park, C. M.; Lee, J. S.; Kang, K. Y.; Park, J. Org. Lett. 2005, 7, 1077. (b) Kwon, M. S.; Kim, N.; Seo, S. H.; Park, I. S.; Cheedrala, R. K.; Park, J. Angew. Chem. Int. Ed. 2005, 44, 6913. (c) Kwon, M.; Kim, S.; Park, S.; Bosco, W.; Chidrala, R. K.; Park, J. J. Org. Chem. 2009, 74, 2877.

17. Chang, F.; Kim, H.; Lee, B.; Park, S.; Park, J. Tetrahedron Lett. 2010, 51,4250

18. (a) Wang, J.; Zhu, Z.; Huang, W.; Deng, M.; Zhou, X. J. Organomet Chem. 2008, 693, 2188. (b) Pri-Bar, I.; James, B. R. J. Mol. Catal. A 2007, 264, 135.

19. Hara, T.; Mori, K., Oshiba, M.; Mizugaki, T., Ebitani, K.; Kaneda, K. Green Chem. 2004, 6, 507.

20. All reactions were carried out in a small $(10 \mathrm{~mL})$ and flame-dried glassware. $\mathrm{Pd} / \mathrm{AlO}(\mathrm{OH})(1.00 \mathrm{wt} \%)$ was prepared by the literature method. ${ }^{16 \mathrm{a}} \mathrm{GC}$ analysis was performed on an ACME $6000 \mathrm{GC}$ equipped with THERMO TR-WaxMS column $(30 \mathrm{~m} \times$ $0.25 \mathrm{~mm}$ ID $\times 0.25 \mu \mathrm{m})$ and FID detector. Typical procedure of solvent-free dehalogenation of 4-chlorophenol is described as follows: the mixture of solid 4-chlorophenol $(0.2 \mathrm{mmol})$ and $\mathrm{Pd} /$ $\mathrm{AlO}(\mathrm{OH})(2.0 \mathrm{~mol} \%$ of $\mathrm{Pd})$ was ground finely with a mortar and pestle at ambient temperature before use, and then put into a glassware equipped with a rubber septa, followed by sealing with parafilm. Nitrogen gas was charged into the reactor for several times to expel air and then expelled by atmospheric pressure of hydrogen. The mixture was allowed to react for a desired time without controlling the temperature in the vessel. After filtering the catalyst, the product analyses were performed using GC and ${ }^{1} \mathrm{H}$ NMR by comparing to the authentic samples. Dehalogenation in organic solvents: the mixture of 4-chlorophenol and $\mathrm{Pd} /$ $\mathrm{AlO}(\mathrm{OH})(2.0 \mathrm{~mol} \%$ of $\mathrm{Pd})$ in organic solvent $(3 \mathrm{~mL})$ was exposed to atmospheric hydrogen environment at room temperature. After reaction, the analysis procedure was the same as described above.

21. Studer, M.; Blaser, H. U. J. Mol. Catal. A 1996, 112, 437.

22. Aramendia, M. A.; Borau, V.; Garcia, I. M.; Jimenez, C.; Lafont, F.; Marinas, A.; Marinas, J. M.; Urbano, F. J. J. Mol. Catal. A 2002, 184, 237.

23. (a) Levine, M.; Temin, S. C. J. Org. Chem. 1957, 22, 85. (b) Koo, J. J. Am. Chem. Soc. 1953, 75, 720 . 